\title{
Een beschouwing over externe financiële verslaggeving door beleggingsinstellingen
}

\author{
Dr. G.J.M. Braam
}

\section{Inleiding}

Ondanks formeel correcte navolging van de regelgeving met betrekking tot de externe financiële verslaggeving door beleggingsinstellingen, blijkt het beeld dat op basis van een jaarrekening van een beleggingsinstelling wordt gevormd misleidend te kunnen zijn. Dit artikel bevat een beschouwing over een aantal aspecten van deze verslaggeving.

Het eerste beleggingsfonds ter wereld 'Eendragt maakt Magt' - werd opgericht in 1774 te Amsterdam. In 1936 werd in Nederland voor het eerst een beleggingsinstelling aan de beurs genoteerd. Eind 1998 waren in Nederland deelnemingsbewijzen verkrijgbaar van meer dan 900 beleggingsinstellingen, waarvan ruim 270 instellingen waren genoteerd aan de Amsterdam Exchanges. Qua functioneren kunnen beleggingsinstellingen worden beschouwd als intermediairs tussen deelnemers en beleggingsobjecten. Deelnemers zijn aandeelhouder of deelgerechtigde in een beleggingsinstelling. Beleggingsinstellingen beleggen de verkregen gelden collectief in een aantal beleggingsobjecten teneinde de deelnemers in de opbrengsten van de beleggingen te doen delen. Om de deelnemers te informeren over de uitkomsten van het gevoerde beleid, stellen beleggingsinstellingen externe financiële verslagen op, zoals de externe financiële jaarrekening (verder genoemd: 'de jaarrekening').

De dissertatie Externe financiële verslaggeving door beleggingsinstellingen (1998) besteedt aandacht aan deze informatieverstrekking. In de dissertatie is onderzocht welke gegevens (moeten) worden verstrekt in de externe financiële verslagen en in hoeverre de kwaliteit van deze verslaggeving kan worden verbeterd opdat deelnemers relatief meer verantwoorde beslissingen kunnen nemen over kopen, aanhouden en verkopen van deelnemingsbewijzen van beleggingsinstellingen. In het vervolg van dit artikel, dat met name is gebaseerd op deze dissertatie, wordt een aantal, met elkaar samenhangende onderwerpen besproken. Deze onderwerpen zijn: de bepaling van de grootte van resultaat en performance, de verwerking van ingekochte eigen aandelen en het geven van inzicht in verbanden. Ten aanzien van deze onderwerpen wordt de vraag beantwoord of, gegeven de doelstellingen van externe financiële verslaggeving door beleggingsinstellingen, de regelgeving met betrekking tot de verslaggeving adequaat is. Een en ander wordt geïllustreerd aan de hand van een voorbeeld. Voor een beschrijving van andere aspecten van de verslaggeving, zoals de wijze(n) waarop een jaarrekening van een beleggingsinstelling inzicht geeft of kan geven in risico en de verhoudingen tussen rendement en risico, verwijs ik naar de dissertatie.

\section{Bepaling van de grootte van resultaat en performance}

Deelnemers van beleggingsinstellingen worden verondersteld te streven naar optimale verhoudingen tussen rendement en risico. Mede om de deelnemers hierover te informeren, toont een winst- en verliesrekening van een beleggingsinstelling het resultaat na belastingen. Het resul-

Dr. G.J.M. Braam, registeraccountant, is werkzaam als universitair hoofddocent aan de Nijmegen Business School van de Katholieke Universiteit Nijmegen. 
taat na belastingen geeft een totaal van waardeverandering van het eigen vermogen weer, niet zijnde kapitaalstortingen of onttrekkingen.

Dit totaal bestaat - of kan bestaan - uit de volgende componenten:

directe opbrengsten uit beleggingen. Directe opbrengsten uit beleggingen - ook wel inkomsten uit beleggingen genoemd bestaan uit (nog te) ontvangen dividenden, renten en huren: waardeveranderingen van beleggingen. Waardeveranderingen van beleggingen treden op ten gevolge van veranderingen in de marktwaarden (reële waarden) van de beleggingen. De waardeveranderingen kumnen daarbij waardevermeerderingen en waardeverminderingen betreffen en kunnen gerealiseerd of niet gerealiseerd zijn op grond van het wettelijke realisatiebeginsel (artikel 2:384 lid 2 BW);

overige bedrijfsopbrengsten. Overige bedrijfsopbrengsten omvatten onder meer opbrengsten van expliciete opslagen en afslagen voor kosten, opbrengsten van nieuwe financiële instrumenten, opbrengsten van heruitgifte van eigen aandelen en provisies uit hoofde van verbruikleen van elfecten en opbrengsten van andere activa;

bedrijfslasten. Bedrijfslasten omvatten beheerkosten, transactiekosten en oprichtings- en emissiekosten;

belastingen. Het al dan niet moeten betalen van vemnootschapsbelasting is allhankelijk van de fiscale status van een beleggingsinstelling'.

Bij het informeren van deelnemers door middel van een jaarrekening, dient een beleggingsinstelling te voldoen aan normen die in het maatschappelijk verkeer als aanvaardbaar worden beschouwd. Deze normen kunnen wettelijke en buitenwettelijke normen betreffen. Voorbeelden van wettelijke normen zijn Titel 9 Boek 2 BW. algemene maatregelen van bestuur, de Wet toezicht beleggingsinstellingen ( W $(b)$ en het daarop gebaseerde Besluit toezicht beleggingsinstellingen ( $\mathrm{Btb}$ ) en de (supranationale) richtlijnen van de Europese Unie (voorheen de EEG-richtlijnen genaand). Voorbeelden van buitenwettelijke normen zijn de Richtlijnen van de Raad voor de Jaarverslaggeving (R.J), zoals

Tabel 1: Overzicht van bepalingen uit wet- en regelgeving op grond warvan waardeveranderingen van het eigen vermogen, niet zijnde kapitaalstortingen en onttrekkingen, in een winst- en verliesrekening of direct als mutatie in het eigen vermogen mogen worden verantwoord

\begin{tabular}{|c|c|c|c|c|}
\hline \multirow{3}{*}{$\begin{array}{l}\text { Componenten tam } \\
\text { resulkut ma belastingen }\end{array}$} & \multicolumn{4}{|c|}{ 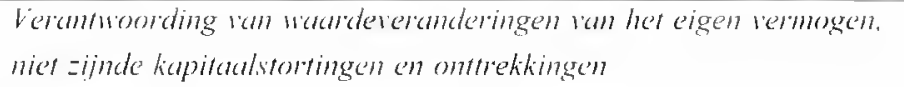 } \\
\hline & \multicolumn{2}{|c|}{$\begin{array}{l}\text { Vermmoording in de } \\
\text { winst-en ierliesrekening }\end{array}$} & \multicolumn{2}{|c|}{$\begin{array}{l}\text { Verantwerding direct in } \\
\text { het eigen vermogen }\end{array}$} \\
\hline & Wetgering & RJ. 1909 & Wetgeving & R.I. 1009 \\
\hline Directe opbrengsten uit beleggingen & (1). (3) & 615.306 & & \\
\hline Waardeveranderingen vall beleggingen: & $(2),(3)$ & 615.300 & & 615.308 \\
\hline - Waardedalingen & & & $(4) \longrightarrow(3)$ & 309 \\
\hline Waardestijgingen: & $(1) \cdot(3)^{2}$ & 615.306 & & \\
\hline gerealiseerd & (3) & 615.306 & $(4) \longrightarrow(3)$ & 015308 \\
\hline \multirow[t]{3}{*}{ niel gerealiseerd } & & & $(4) \rightarrow(3)$ & 309 \\
\hline & & & & 615.308 \\
\hline & & & & $3(09$ \\
\hline Overige bedrijfsopbrengsten & $(1) .(3)$ & 615.306 & & \\
\hline \multirow[t]{2}{*}{ Bedrijfilasten } & (3) & 615.310 & & $615.316-$ \\
\hline & & 321 & & 320 \\
\hline Belastingen & (3) & 615.403 & & \\
\hline
\end{tabular}

Toelichting:

(1) = artikel 2:384 lid 2 BW: beschouwd als gerealiseerd op grond van dit wettelijke realisatiebeginsel:

(2) = artikel 2:384 lid $2 \mathrm{BW}$ : wettelijk roorzichtigheidsbeginsel:

(3) = Model S van Besluit modellen jaarrekening:

$(4)=$ artikel 2:401 lid 2 BW en artikel $16 \mathrm{~b}$ lid 3 Besluit modellen jalarrekening. 
Richtlijn 615 'Beleggingsinstellingen', en richtlijnen van het International Accounting Standards Committee (IASC). Uit tabel I blijkt op basis van welke bepalingen uit de genoemde wet- en regelgeving de beschreven componenten in de winst- en verliesrekening (moeten) worden opgenomen. Uit tabel 1 blijkt verder dat waardeveranderingen van beleggingen ook direct als mutatie van het eigen vermogen - buiten de winst- en verliesrekening om

kumnen worden verantwoord. Deze waardeveranderingen worden dan bijvoorbeeld verantwoord in een post koersverschillenreserve (artikel 2:401 lid 2 $\mathrm{BW}$ ). In geval de waardeveranderingen niet in de winst- en verliesrekening worden verantwoord, wordt op grond van artikel 16 b lid 3 Besluit modellen jaarrekening mede ten behoeve van de vergelijkbaarheid onder de telling van de winst- en verliesrekening een post Wijziging in de reserves uit hoofde van koersverschillenreserve opgenomen.

Uit het navolgende voorbeeld blijkt dat het beeld dat op grond van de in tabel I (zie pagina 44) genoemde bepaling over de uitkomsten van gevoerd beleid kan worden gevormd. misleidend kan zijn. De gegevens uit het voorbeeld zijn ontleend aan de jaarverslagen 1993-1998 van de beleggingsinstelling die in Nederland de grootste is. gemeten naar marktkapitalisatie. De desbetreffende beleggingsinstelling is een fiscale beleggingsinstelling. Er wordt om die reden geen vennootschapsbelasting betaald. In het voorbeeld worden waardeveranderingen van beleggingen verantwoord in een koersverschillenreserve. Conform model $S$ wordt onder de nettowinst. zijnde het resultaat (na belastingen), een post $w$ ijziging in de reserves uit hoofde $v$ an koersverschillen getoond. Deze twee posten worden niet getotaliseerd, hetgeen ook niet verplicht is (doch wel aanbeveling verdient (RJ. 1999:615.309)). In tabel 2 worden de componenten nettowinst - en haar samenstellende bestanddelen directe opbrengsten uit beleggingen en beheerkosten - en wijzigingen in de reserves uit hoofde van koers- en overige verschillen getoond voor de jaren 1993-1998. Op basis van deze label kunnen de volgende conclusies worden getrokken: de hoogste nettowinst is behaald in 1995. Indien de componenten nettowinst en wijzigingen in de reserves uit hoofde van koers- en overige verschillen zouden worden getotaliseerd, lijkt 1997 het beste beleggingsjaar.

Echter, indien ook de performance wordt
Tabel 2 Winst- en verliesrekening 1993-1998

(bedlagen in NLG; $x$ milj.)

\begin{tabular}{|c|c|c|c|c|c|c|}
\hline & 1098 & 1997 & 1996 & 1995 & 1994 & 1993 \\
\hline \multicolumn{7}{|c|}{ Direcke ophrengsten } \\
\hline uit beleggingen & 186 & 207 & 285 & 3.37 & 307 & 303 \\
\hline Beheerkosten & 31 & 29 & 26 & 24 & 27 & 25 \\
\hline Nettowinst & 155 & 178 & 259 & 313 & 280 & 278 \\
\hline \multicolumn{7}{|c|}{ Wijzigingen uil hoofde } \\
\hline \multicolumn{7}{|c|}{ van koers- en overige } \\
\hline verschillen & 2.460 & 3.418 & 2.306 & 409 & -1.109 & 2.313 \\
\hline
\end{tabular}

getoond. kan een andere conclusie worden getrokken over de uitkomsten van gevoerd beleid. De performance over een periode is het bedrag waarmee het eigen vermogen in de desbetreffende periode is veranderd als wordt afgezien van kapitaalstortingen en onttrekkingen. De performance van een beleggingsinstelling is gelijk aan de algebraïsche som van de componenten directe opbrengsten uit beleggingen plus waardeveranderingen van beleggingen plus overige bedrijfsopbrengsten minus bedrijislasten en belastingen. De samenstellende componenten van de performance zijn dezelide als de reeds beschreven componenten van het resultaat na belastingen. Resultaal (na belasting) is daarbij het deel van de performance dat voor uitkering in aammerking komt. Als de performance volledig uitkeerbaar is, is het resultaat (na belasting) gelijk aan de performance (Braam, 1998: 156-166; zie ook Brezet, 1986:17; Klaassen, 1997a en 1997b). In tabel 3 (zie pagina 46) worden de nettowinst en wijzigingen uit hoofde van koers- en overige verschillen, hun subtotaal en de performance getoond. Beoordeeld op basis van de performance, zijn de beste uitkomsten van gevoerd beleid niet behaald in 1995 of 1997, maar in 1993.

Uit het roorbeeld blijkt dat ondanks formeel correcte navolging van de regelgeving met betrekking tot de externe financiële verslaggeving door beleggingsinstellingen, het beeld dat op basis van een jaarrekening over de uitkomsten van gevoerd beleid word gevormd misleidend kan zijn. Door middel van winst- en verliesrekeningmodel $\mathrm{S}$ kan mijns inziens de suggestie worden gewekt dat de totaaluitkomst van gevoerd beleid een andere uitkomst is dan de 'werkelijke uitkomst'. Mede op grond van het voorgaande lijkı het mij wenselijk dat de winst- en verliesrekening van een beleggingsinstelling naast het 
Tabel 3: Nettowinst, wijzigingen uit hoofde van koers- en overige verschillen en performance 1993-1998

(bedragen in NLG $x$ miljoen)

\begin{tabular}{rrrrrrr}
\hline & 1998 & 1997 & 1996 & 1995 & 1994 & 1993 \\
\hline Nellowinst & 155 & 178 & 259 & 313 & 280 & 278
\end{tabular}

Wijzigingen uit hoorde

van koers- en overige

$\begin{array}{lllllll}\text { verschillen } & 2.460 & 3.418 & 2.306 & 409 & -1.109 & 2.313\end{array}$

Nellowinst en Wijzi-

gingen uil hoofde van

koers- en overige

$\begin{array}{lllllll}\text { verschillen } & 2.615 & 3.596 & 2.565 & 722 & -829 & 2.591\end{array}$

Deel perlormance niet

getoond in of onder

de winst- en

\begin{tabular}{lrrrrrr} 
verliesrekening (1) & -1.076 & -1.668 & -1.789 & -118 & & \\
\cline { 2 - 6 } Perlormance & 1.539 & 1.928 & 776 & 604 & -829 & 2.591
\end{tabular}

Toulichting:

(1) = de bedragen bij de post 'Deel performance niel getoond in of onder de winst- en verliesrekening zijn ontleend aan de toclicluting op het eigen vermogen uit de jaarrekeningen 1993-1998. Voor een nadere toelichting zie paragraat 3 .

resultaat na belastingen en de samenstelling van dit resultaat - ook de grootte van de performance en haar afleiding uit samenstellende componenten moet weergeven.' Met behulp van winst- en verliesrekeningmodel $\mathrm{S}$ kan een beleggingsinstelling overigens reeds in één overzicht en de grootte van de performance en het resultalat na belastingen en de samenstellende componenten van deze prestatie-indicatoren tonen. Ten behoeve van de vergelijkbaarheid en - daarmee - uit hoofde van het inzichtvereiste zou dit mijns inziens dus ook verplicht moeten worden (zie ook Korf, 1996:53). Omwille van de duidelijkheid vraag ik mij daarbij af of een dergelijk overzicht niet een andere benaming zou moeten hebben. zoals 'performance-overzicht'.+

Zoals beschreven mogen waardeveranderingen van beleggingen (gerealiseerd en niet gerealiseerd) in de winst- en verliesrekening worden verantwoord maar kunnen zij ook direct als mutatie van het eigen vermogen worden verantwoord. Er zijn dus twee verwerkingsmethoden toegestaan. Gegeven de doelstellingen van de externe financiële verslaggeving lijkt mij dat altijd voor de eerste methode moet worden gekozen. Mijns inziens moeten waardever- anderingen van de beleggingen altijd met behulp van de winst- en verliesrekening (of een performance-overzicht) worden toegerekend aan de perioden waarin het risico dat samenhangt met deze waardeveranderingen wordt gelopen.' Deze verwerkingswijze stemt verder overeen met 'nieuwe' regels van het IASC, 1999 (zie ook IASC, 1995; FASB, 1998a en 1998b; Hoogendoorn, 1997, 1998 en 1999: Hoogendoorn en Böhmer, 1999). Paragraaf 3 bevat een toelichting op de in tabel 3 getoonde verschillen tussen de performance en het totaal van de nettowinst en de wijzigingen in de reserves uit hoofde van koersen overige verschillen.

\section{Verwerking van ingekochte eigen aandelen}

De beleggingsinstelling uit het voorbeeld is een open end beleggingsmaatschappij ${ }^{6}$. Dit betekent dat zij de verplichting heeft op aanvraag van het publiek doorlopend eigen aandelen (rechten van deelneming) uit te geven en in te kopen? Met betrekking tot de verwerking van ingekochte eigen aandelen bestaan op grond van wetgeving en Richtlijnen (artikel 2:373 lid 3 en 385 lid 5 BW; artikel 9 en 10 Vierde EEGRichtlijn; RJ, 1999:240.105-I11 en 615.413-422) de volgende methoden:

1) de waarde van de ingekochte eigen aandelen wordt in mindering gebracht op de overige reserves;

2) de nominale waarde van de ingekochte eigen aandelen wordt in mindering gebracht op het geplaatste kapitaal en het verschil tussen de nominale waarde en de verkrijgingsprijs van de ingekochte eigen aandelen op het agio. De R.J ( 1999:615.414) stelt ingeval van inkoop van eigen aandelen bij open end beleggingsinstellingen deze methode voor, ofschoon methode 2) in Nederland niet is toegestaan op grond van artikel 2:373 lid $3 \mathrm{BW}$;

3) de eigen aandelen worden geactiveerd. Op grond van artikel 9 en 10 Vierde EEG-Richtlijn dient er ter grootte van het geactiveerde bedrag een wettelijke reserve te worden gevormd (ten laste van de vrije reserves). Het IASC maakt hier evenwel geen melding van. Methode 3 ) is in Nederland niet toegestaan op grond van artikel 2:385 lid 5 BW.

Inkoop van eigen aandelen kan geschieden met 
en zonder de intentie deze aandelen te heruitgeven. Als de inkoop van eigen aandelen geschiedt zonder de intentie deze aandelen te heruitgeven, kan de transactie worden beschouwd als een 'intrekking' van eigen aandelen. Als de inkoop van eigen aandelen geschiedt met de intentie deze aandelen te heruitgeven, zoals grosso modo het geval is bij open end beleggingsinstellingen, kan de transactie worden beschouwd als een (tijdelijke) belegging. Door de inkopen van eigen aandelen te zien in samenhang met de heruitgifte van deze aandelen, kunnen de inkopen worden beschouwd te resulteren in een bijzondere handelspositie, namelijk beleggingen in eigen aandelen (Braam, 1998:271279). De verwerking, presentatie en toelichting dient mijns inziens dan ook te geschieden overeenkomstig de wijze van verantwoorden van de beleggingen niet in eigen aandelen. De ingekochte eigen aandelen dienen derhalve, overeenkomstig de derde methode, te worden geactiveerd. Ter grootte van het geactiveerde bedrag zou uit hoofde van kapitaalbescherming een wettelijke reserve kunnen worden gevormd. ${ }^{8}$

Een implicatie van deze beschouwingswijze is dat verschillen tussen de heruitgifteprijzen en de verkrijgingsprijzen van aandelen worden beschouwd als resultaat en als zodanig in een resultatenrekening (of een performance-overzicht) worden verwerkt. Zeker indien een open end beleggingsinstelling veelvuldig eigen aandelen inkoopt en (later weer) verkoopt, kan het geven van inzicht in de resultaten behaald met deze transacties materieel zijn. Zo blijkt uit tabel 4 dat de beleggingsinstelling uit het voorbeeld in 1998 een verlies op de inkoop en heruitgifte van eigen aandelen heeft gemaakt van $f-1.076=$ $f-2.140+f 1.064$ (x miljoen). In 1995, 1996 en 1997 waren de verliezen behaald door inkoop en heruitgifte van eigen aandelen respectievelijk $f-118, f-1.789$ en $f-1.668$ (x miljoen) (tabel 3).

Uit het voorgaande blijkt dat de keuze voor een verwerkingsmethode een significante invloed kan hebben op gepresenteerde prestatiecijfers, hetgeen weer materiële consequenties kan hebben voor daarop gebaseerde oordeels- en besluitvorming. De gegevens over ingekochte en (her)uitgegeven aandelen worden echter wel getoond in de toelichtingen in de jaarrekeningen van de beleggingsinstelling uit het voorbeeld (zie de tabellen 3 en 4). De vraag kan niettemin worden gesteld in hoeverre de gegevens, op deze wijze getoond, begrijpelijk en toegankelijk zijn voor deelnemers en analisten. In paragraaf 4 wordt een voorstel gedaan om de transparantie van de jaarrekening te vergroten.

\section{Inzicht in verbanden}

Uit het voorbeeld beschreven in de paragrafen 2 en 3 blijkt reeds dat in 1995-1998 het totaal van de mutaties van de koersverschillenreserve niet gelijk is aan het bedrag getoond in de post Wijzigingen uit hoofde van koers- en overige verschillen onder de winst- en verliesrekening. Uit empirisch onderzoek blijkt verder dat het verband tussen de mutaties van het eigen vermogen, zoals mutaties verwerkt in de koersverschillenreserve, en de koers- en valutaresultaten behaald met de beleggingen vaak niet kan worden afgeleid (Braam en Van Hoepen, 1996:165-171; Braam, 1998:266). ${ }^{9}$

Zo blijkt ingeval van het voorbeeld uit tabel 4 dat de mutatie in de koersverschillenreserve, niet uit hoofde van ingekochte en (her)uitgegeven aandelen $f 2.460$ miljoen bedraagt. Uit de toe-

Tabel 4: Toelichting op de samenstelling van het eigen vermogen 1998 (bedragen in NLG $x$ miljoen)

\begin{tabular}{|c|c|c|c|c|c|c|}
\hline & $0 / / 01 / 1998$ & & Mutaties & & & $31 / / 2 / 1998$ \\
\hline & & $\begin{array}{l}\text { Betaald op } \\
\text { ingekochte } \\
\text { aandelen }\end{array}$ & $\begin{array}{r}\text { Ontvangen } \\
\text { op geplaatste } \\
\text { aandelen }\end{array}$ & $\begin{array}{c}\text { Koers- en } \\
\text { valuta- } \\
\text { resultaal }\end{array}$ & Overige & \\
\hline Geplaatst kapitaal & 634 & -106 & 54 & - & - & 582 \\
\hline Koersverschil- & & & & & & \\
\hline lenreserve & 10.803 & -2.140 & 1.064 & 2.460 & - & 12.187 \\
\hline Overige reserves & 435 & - & - & - & - & 435 \\
\hline Onverdeelde winst & 11 & - & - & - & -10 & 1 \\
\hline Totaal & 11.883 & -2.246 & 1.118 & 2.460 & -10 & 13.205 \\
\hline
\end{tabular}


lichting op de beleggingen in de jaarrekening 1998 blijkt uit het mutatie-overzicht belegging dat de koers- en valutaresultaten (gerealiseerd en niet gerealiseerd) over 1998 bedragen $f 2.621$ miljoen. Het verschil betreft een koers- en valuta'verlies' van $f 161$ miljoen. Uit de toelichting in de jaarrekening blijkt dat dit verschil onder meer moet kunnen worden verklaard door resultaten behaald met nieuwe financiële instrumenten die niet in het mutatie-overzicht beleggingen zijn verwerkt, doch wel in het mutatie-overzicht eigen vermogen, of wel in het mutatie-overzicht beleggingen zijn verwerkt maar niet in het mutatieoverzicht eigen vermogen. Een expliciete verklaring voor dit verschil bevat de jaarrekening niet.

Het lijkt mij wenselijk dat mutaties van het eigen vermogen zodanig worden gepresenteerd en toegelicht dat de verbanden tussen het mutatieoverzicht van het eigen vermogen, de winst- en verliesrekening en de koers- en valutaresultaten behaald met beleggingen en resultaten behaald met overige activa en passiva duidelijk blijken (zie ook Van Hoepen, 1988:19-22: NIVRA. 1989:18-20; Braam en Van Hoepen, 1997:157; RJ, 1999:615.402: Braam. 1999:266-267 en 280). Door de desbetreffende verbanden inzichtelijk te maken, neemt de transparantie van het externe jaarverslag toe. Daarbij geeft de jaarrekening dan wellicht meer inzicht in resultaten behaald met nieuwe financiële instrumenten. Hierdoor verbetert mijns inziens de kwaliteit van de externe financiële verslaggeving. Kwaliteitsverbetering van de verslaggeving betekent dat de doelstellingen van de verslaggeving beter worden verwezenlijkt. Immers, kwaliteitsverbetering impliceert een meer verantwoorde oordeelsvorming omtrent vermogen, resultaat, nadere specificaties met betrekking tot de financiële positie en risico en - daardoor - een meer verantwoorde besluitvorming omtrent het kopen, aanhouden en verkopen van deelnemingsbewijzen van een beleggingsinstelling.

\section{Slot}

In dit artikel is een beschouwing gegeven over externe financiële verslaggeving door beleggingsinstellingen. Gegeven de doelstellingen van de verslaggeving door beleggingsinstellingen is ten aanzien van een aantal aspecten van de regelgeving met betrekking tot de verslaggeving de vraag beantwoord of deze regelgeving adequaat is. Uit de paragrafen 2-4 blijken onvolkomenheden in de regelgeving in de bestaande verslaggevingspraktijk tot uitdrukking te kunnen komen bij de bepaling en de presentatie van resultaat (performance) en de toelichting hierop. Teneinde de geconstateerde onvolkomenheden te ondervangen, bevat het artikel een aantal voorstellen gericht op verbetering van de kwaliteit van externe financiële verslaggeving door beleggingsinstellingen. Op basis van deze voorstellen zou ook de kwaliteit van de externe verslaggeving door andere financiële instellingen en door nietfinanciële instellingen kunnen worden verbeterd. Daarnaast kunnen de voorstellen ten uitvoer worden gebracht in geval van interne financiële verslaggeving. Nader onderzoek met betrekking tot verbetering van de kwaliteit van de financiële verslaggeving is aan te bevelen.

\section{I T E RAT U U R:}

Beckman, H., (1987), De jaarrekening. Bedriffseconomische, juridische en fiscale aspecten, Stenfert Kroese, Leiden/ Antwerpen.

Beckman, H., (1998), Interpretatieve mededeling van de Europese Commissie inzake de jaarrekeningrichtlijnen, TVVS, april: pp. 113-115.

Beckman, H., A.J. Bindenga, W.M. Meijer, F. Krens en H. Smits (redactie), Compendium voor de jaarrekening. Wegwiizer voor de praktijk, Kluwer, Deventer, losbladig.

Braam, C.J.M. en M.A. van Hoepen, Externe verslaggeving van beleggingsinstellingen, in: J.A.G.M Koevoets, L.G. van der Tas en R.G.A Vergoossen (redactie), (1997) Het jaar 1996 verslagen. Onderzoek jaarverslaggeving Nederlandse ondernemingen, Kluwer/Koninklijk NIVRA, Deventer: pp143-174.

Braam, G.J.M., (1998), Externe financiële verslaggeving door beleggingsinstellingen, dissertatie, Kluwer, Deventer.

Brezet, J.C., (1986), Micro-economische en bedrijfseconomische winstbepaling, Bedrijfseconomisch Instituut van de Erasmus Universiteit Rotterdam, dissertatie, Rotterdam.

Europese Commissie, Interpretatieve mededeling over bepaalde artikelen van de Vierde en de Zevende Richtlijn van de Raad betreffende de jaarrekening, Publicatieblad van de Europese Cemeenschappen, 20 januari 1998.

Financial Accounting Standards Board (FASB), (juni 1997), Statement of Financial Accounting Standards 130, Reporting comprehensive income, Stamford $\mathrm{Ct}$. 
Financial Accounting Standards Board (FASB), (januari 1998a), Reporting financial performance: current developments and future directions, Stamford $\mathrm{Ct}$.

Financial Accounting Standards Board (FASB), (juni 1998b), Statement of Financial Accounting Standards 133, Accounting for derivative instruments and hedging activities, Stamford Ct.

Garderen, E.J. van, (april 1995), Inkoop van eigen aandelen en de vrije ruimte bij beleggingsmaatschappijen, Maandblad voor Accountancy en Bedrijfseconomie: pp. 262-266.

Hoepen, M.A. van, (1988), De jaarrekening van beleggingsinstellingen, oratie, Wolters-Noordhoff, Groningen.

Hoogendoorn, M.N., (juli/augustus 1997), Aandeelhouderswaarde en jaarrekening, Maandblad voor Accountancy en Bedrifseconomie: pp. 334-335.

Hoogendoorn, M.N., (1998) Financiële instrumenten: een revolutie voor de jaarrekening, Maandblad voor Accountancy en Bedrijfseconomie, juli/augustus: pp. 361-363. Hoogendoorn, M.N., (1999), Een modeljaarrekening op basis van aandeelhouderswaarde, in: Bericht Gegeven, A.J. Bindenga, M.A. van Hoepen en J. Maat (redactie), Kluwer, Deventer: pp. 195-212.

Hoogendoorn, M.N. en S. Böhmer, (1999), Financiële instrumenten in de jaarrekening: de stand van zaken in 1999, Tiidschrift voor Bedrijfsadministratie, juni: pp. 214-221. International Accounting Standards Committee (IASC), (juni 1995), International Accounting Standard 32, Financial instruments: disclosure and presentation, Londen.

International Accounting Standards Committee (IASC), (februari 1999), International Accounting Standard 39, Financial instruments: recognition and measurement, Londen.

Klaassen, J., (oktober 1997a), Financiële positie, resultaat en financiële performance, Maandblad voor Accountancy en Bedriffseconomie: pp. 508-516.

Klaassen, J., (1997b), Financiële positie, resultaat en financiële performance, in: M.P.B. Bonnet, A. de Bos en J. Maat (redactie), Fma-Kroniek 1997, Samsom, Rotterdam: pp. 316.

Korf, D., (1996), Nieuwe verslaggevingsvoorschriften voor beleggingsinstellingen, Maandblad voor Accountancy en Bedriffeconomie, januari: pp. 51-57.

Nederlands Instituut van Registeraccountants (NIVRA), (1989), Commissie van Advies inzake Jaarverslaggeving, Subcommissie Beleggingsinstellingen, Knelpunten in Titel 9. Boek 2 Burgerliik Wetboek met betrekking tot Beleggingsmaatschappijen, NIVRA, Amsterdam.

Raad voor de Jaarverslaggeving (RJ), (editie 1999), Richtliinen voor de Jaarvers/aggeving, Kluwer, Deventer.

\section{NOTEN}

1 Voor fiscale beleggingsinstellingen geldt voor de heffing van de vennootschapsbelasting het nultarief (artikel $28 \mathrm{Vpb}$ en het daarop gebaseerde Besluit beleggingsinstellingen). Hierdoor worden fiscale beleggingsinstellingen materieel buiten de heffing van de vennootschapsbelasting geplaatst, ofschoon ze formeel vennootschapsbelastingplichtig blijven. Voor beleggingsmaatschappijen en open beleggingsfondsen die niet de status van fiscale beleggingsinstelling hebben gelden de normale vennootschapsbelastingtarieven. Voor nadere toelichting, zie Braam, 1998: 54-63.

2 Zie ook Europese Commissie, 1998:alinea 38-40; Beckman, 1998:114.

3 Voor een beschrijving van de presentatie van de grootte en samenstelling van de performance en toelichting hierop, verwijs ik naar Braam, 1998:238-249 en 283-286 (zie ook FASB, 1997).

4 De Nota van toelichting bij het Besluit modellen jaarrekening meldt ten aanzien van dit punt: 'In overeenstemming met de eisen die de vierde richtlijn vennootschapsrecht stelt, blijft sprake van een winst- en verliesrekening ...'.

5 Dit impliceert overigens wel dat de koersverschillenreserve in het kader van bepaling van de grootte van de performance geen functie meer heeft en dat de post Wijziging in de reserves uit hoofde van koersverschillenreserve bij de presentatie onder de winst- en verliesrekening geen functie meer heeft.

6 Een beleggingsmaatschappij is een beleggingsinstelling met rechtspersoonlijkheid. Een beleggingsinstelling zonder rechtspersoonlijkheid is een beleggingsfonds.

$7 \mathrm{lk}$ merk hierbij overigens op dat beleggingsfondsen geen in aandelen verdeeld kapitaal hebben. Omwille van de duidelijkheid spreek ik niettemin in het vervolg van dit artikel over de begrippen geplaatst en aandelen, waarmee tevens het door deelnemers in een beleggingsfonds bijeengebrachte fondsvermogen, respectievelijk deelnemingsbewijzen van deelgerechtigden in een beleggingsfonds worden bedoeld.

8 Voor een nadere toelichting op methode 3), alsmede een aanvulling op deze methode verwijs ik naar Braam, 1998:274-279; zie ook Beckman, 1987:211; Van Garderen, 1995:264-265; Compendium, 1996:paragraaf 4.4.8.

9 De koers- en valutaresultaten behaald met de beleggingen moeten op grond van artikel 21 lid $1 \mathrm{a}$ Btb worden getoond in de toelichting op de beleggingen (zie ook RJ, 1998: 6.15.404; artikel 44 lid 1b Btb; Braam, 1998:263-267). 